Original article

\title{
Detoxical aspects of nutritional therapy using natural enterosorbents on the basis of pectins
}

\author{
Elena E. Tekutskaya \\ Kuban State University, Krasnodar, Russia \\ Received 12 July 2013, Accepted 2 August 2013
}

(C) 2013, Tekutskaya E.E.

(C) 2013, Russian Open Medical Journal

\begin{abstract}
The rate of anthropogenic pollution and reduction of the environmental quality progress quicker than adaptive possibilities of an organism. This causes pre-pathological and pathological changes. So there is a necessity of preventive measures organization to eliminate toxic load and accelerated eliminating of xenobiotics from an organism. The discoveries of the recent 15 years had been revealed the possibility to change complexons (which are used for detoxication) to dietary fibers, pectin as well. Meanwhile pectin substances are not widely used in clinical practice, and their efficiency comparing with small concentrations of cumulating poisons had not been studied yet. During the development of the detoxification nutritional therapy at patients with different pathology of the digestive system organs (with the revealed heavy metals and organochlorine pesticides) there had been organized tests of pectin efficiency (citrus and apple) for reducing the contamination with these xenobiotics. After the course of pectin treatment there had been fixed not only the reduce of toxic heavy metals, but essential microelements as well, which is connected with nonselective complexing capability of pectin substances. The probe tests also showed that course of citrus pectin treatment favored total excretion of organochlorine pesticides at $11.0 \%$ of patients, at other patients pesticide level reduced up to minimal rate (revealed by gas chromatographic method $0.0001 \mathrm{mg} / \mathrm{dm}^{3}$ ). There is a significant difference of values before and after pectin treatment. At the same time at patients who had not taken enterosorbent (compare group) the level of organochlorine pesticides after repeated tests stayed on the level close to the basic. There had been discussed mechanism of excretion of organochlorine pesticides and heavy metals with the help of pectins.
\end{abstract}

Keywords: pectins, level of lead, cadmium, zinc, cuprum, organochlorine pesticides, detoxication

Cite as Tekutskaya EE. Detoxical aspects of nutritional therapy using natural enterosorbents on the basis of pectins. Russian Open Medical Journal 2013; 2 : 0306.

Correspondence to Elena E. Tekutskaya. Address: ap. 5, 135, Gagarina Str., Jablonovsky, Adygea, 385141, Russia. Office phone: 88612199566. E-mail: tekytska@mail.ru

\section{Introduction}

The rate of anthropogenic pollution and reduction of the environmental quality progress quicker than adaptive possibilities of an organism. This causes pre-pathological and pathological changes. So there is a necessity of preventive measures organization to eliminate toxic load and accelerated eliminating of xenobiotics from an organism.

Nutritional therapy today should not be estimated only as a resource of nutrients, vitamins and their precursors - separate minerals, essential amino acids and microelements for an organism. The next, no less important positive effect of nutritional therapy components is their capability to link and force the excretion of salts of toxic heavy metals, pesticides, radionuclides [1].

At heavy metals intoxication there had been always used complexons, but the use of them had been accompanied by adverse effects caused by excretion of essential microelements from an organism. The usage of antidotes is limited by their low efficiency of chronic influence of low- dose rates, and negative side effects (microelements disbalance, thrombocytopenia, and nephrosis). For organochlorine pesticides, which are chemically inert and polytropic, there are not any specific antidotes [1].
The discoveries of the recent 15 years had been revealed the possibility to change complexons (which are used for detoxication) to dietary fibers, pectin as well. It is fixed that the deficiency of pectin substances in food is a risk factor of developing such diseases as: gastrointestinal tract disease, diabetes, heart ischemic disease, etc. Detoxification effect of pectins as related to heavy metals and radionuclides had been confirmed by many researches $[2,3]$. Meanwhile pectin substances are not widely used in clinical practice, and their efficiency comparing with small concentrations of cumulating poisons had not been studied yet.

Environmental situation in Krasnodar region (Russia) is determined by serious technogenic pressure on nature complexes, first of all it is caused by the next factors: oil-producing and oilrefining industry, energetic complexes building, traffic flow increase (first of all automobile flow) [4].

At the same time the major part of waste productions (especially lead, cadmium, arsenic) in the region with a high population density (Krasnodar region) intensifies pressure on the environment and invite a real danger for the population, cause the progress of digestive system pathology [5].

The presented study aimed developing of pathogenetically reasonable, safe, effective and comprehensible methods of active 
detoxification with the use of pectins with small concentrations of cumulating poisons.

\section{Material and Methods}

During the development of the detoxification nutritional therapy at patients with different pathology of the digestive system organs (with the revealed heavy metals and organochlorine pesticides) on the base of the Regional clinical hospital there had been organized tests of citrus and apple pectin efficiency ("Medetopekt", translit from Russian) for reducing the contamination with these xenobiotics.

This citrus pectin is presented as a white powder. Certificate of analysis: etherification degree $-69 \%$, polygalacturonic acid level $86 \%, \mathrm{pH} 3.2$ in $25 \%$ water solutions at 20 - $\mathrm{C}$. The developed course dose was $10 \mathrm{~g} 3$ times per day in $50 \mathrm{ml}$ of warm water $20-30 \mathrm{~min}$ before meal (during 10 days).

"Medetopekt" in optimized recipe contains: 35\% lowetherified and $10 \%$ extraetherified apple pectin, insoluble compounds, excipients (magnesium stearate, sorbit, calcium phosphate, vitamin C). An average overall degree of etherification is $30-38 \%$. One pill of "Medetopekt" is $550 \mathrm{mg}$, which is equal to $200 \mathrm{mg}$ of pectin. The course of treatment was: 4 pills 3 times per day (equal to $2-4 \mathrm{~g}$ of pectin) during 7 days, after tertian pause -6 pills 3 times per day (3,6 g of pectin) during 7 days. The course therapy included 210 pils. "Medetopekt" was put on $30 \mathrm{~min}$ before meals with $150-200 \mathrm{ml}$ of water.

The concentration of the salts of lead, cadmium, zinc, and cuprum in spit had been measured with the help of unitized methods of sample processing and ultimate analysis: UV-radiation in photolyzable camera and stripping voltammetry on aglassycarbon electrode $[6,7]$. Concentration of organochlorine pesticides in a whole blood had been measured by method of gasliquid chromatography with the help of chromatograph, according to technology from [8], modified in [9]. All of the examined patients signed written consent for organizing medico-ecological examination according to World Medical Association Declaration of Helsinki.

\section{Statistical analysis}

Results had been done with the help of Statistica 6.0 soft. Mann-Whitney U-test was used. Data presented as mean and standad deviation (SD).

\section{Results}

There had been examined 40 patients with chronic pancreatitis, 20 of them had been taken citrus pectin (group of comparison) and had not been taken enterosorbent. Testing of the efficiency of course dose had been performed controlling the level of cadmium and lead in spit, as well as the level of zinc and cuprum, by method of stripping voltammetry on aglassy-carbon electrode.

After the course of pectin there had been fixed the decrease of toxic heavy metals and essential microelements, which is connected with nonselective complexing capability of pectin substances. There are presented the results of testing of enterosorption pectin activity in relation to heavy metals (Table 1). In the group of compare there had not been any changes of heavy metals level in spit before and after treatment.
Table 1. The levels of lead and cadmium spit before and after the course of citrus pectin, $n=20, p<0.05$

\begin{tabular}{|c|c|c|c|}
\hline \multicolumn{2}{|c|}{$\begin{array}{c}\text { Lead level, } \\
\mathrm{mg} / \mathrm{dm}^{3} \text { of biosubstrate }\end{array}$} & \multicolumn{2}{|c|}{$\begin{array}{c}\text { Cadmium level, } \\
\mathrm{mkg} / \mathrm{dm}^{3} \text { of biosubstrate }\end{array}$} \\
\hline $\begin{array}{l}\text { Before pectin } \\
\text { treatment }\end{array}$ & $\begin{array}{l}\text { After pectin } \\
\text { treatment }\end{array}$ & $\begin{array}{l}\text { Before pectin } \\
\text { treatment }\end{array}$ & $\begin{array}{c}\text { After pectin } \\
\text { treatment }\end{array}$ \\
\hline $0.248 \pm 0.012$ & $0.140 \pm 0.007$ & $0.210 \pm 0.050$ & $<0.010$ \\
\hline
\end{tabular}

Data presented as mean and standad deviation (SD).

Table 2. Concentration of the sum $\alpha-, \beta-, \gamma-\mathrm{HCH}$ in spit of patients with chronic pancreatitis before and after citrus pectin, $\mathrm{mg} / \mathrm{dm}^{3}$ of biosubstrate

\begin{tabular}{|c|c|c|c|}
\hline \multicolumn{2}{|c|}{ Main group, $n=20, p<0.05$} & \multicolumn{2}{|c|}{ Control group, $n=18, p<0.05$} \\
\hline $\begin{array}{l}\text { Before pectin } \\
\text { treatment }\end{array}$ & $\begin{array}{c}\text { After pectin } \\
\text { treatment }\end{array}$ & $\begin{array}{c}\text { The } 1^{\text {st }} \\
\text { determination }\end{array}$ & $\begin{array}{c}\text { The } 2^{\text {nd }} \\
\text { determination }\end{array}$ \\
\hline $0.0050 \pm 0.0007$ & $0.0020 \pm 0.0003$ & $0.0110 \pm 0.0040$ & $0.0100 \pm 0.0044$ \\
\hline
\end{tabular}

$\mathrm{HCH}$ is hexachlorocyclohexane.

Table 3. Dynamic of level change of organochlorine pesticides in whole blood before and after "Medetopekt" treatment, $\mathrm{mg} / \mathrm{dm}^{3}$ of biosubstrate

\begin{tabular}{cccc}
\hline \multicolumn{2}{c}{ Main group, $n=22, p<0.05$} & \multicolumn{2}{c}{ Group of compare, $n=22, p<0.05$} \\
\hline $\begin{array}{c}\text { Before } \\
\text { treatment }\end{array}$ & After treatment & The $1^{\text {st }}$ & The $2^{\text {nd }}$ \\
$0.2700 \pm 0.0083$ & $0.0035 \pm 0.0009$ & $0.0110 \pm 0.0041$ & $0.0100 \pm 0.0049$ \\
\hline
\end{tabular}

\begin{tabular}{|c|c|c|c|c|c|c|c|c|}
\hline \multirow[t]{2}{*}{$\begin{array}{c}\text { Sorbent } \\
\text { name }\end{array}$} & \multicolumn{2}{|c|}{$\begin{array}{l}\text { After } 10 \\
\text { minutes }\end{array}$} & \multicolumn{3}{|c|}{ After saturation } & \multicolumn{3}{|c|}{ Infiltration } \\
\hline & ORP & $\mathrm{pH}$ & ORP & $\mathrm{pH}$ & EC & ORP & $\mathrm{pH}$ & EC \\
\hline $\begin{array}{l}\text { Activated } \\
\text { carbon }\end{array}$ & -85 & 10.4 & -179 & 9.2 & 0.21 & -187 & 8.4 & 0.23 \\
\hline Polyphepan & -247 & 6.9 & -247 & 7.1 & 0.12 & -135 & 7.5 & 0.14 \\
\hline Citrus pectin & -348 & 5.4 & -328 & 5.6 & 6.7 & -295 & 5.7 & 6.6 \\
\hline
\end{tabular}

As had been noted above complexing capability of pectins are mainly studied as metal ions. Taking into consideration that organochlorine pesticides are lyophilic connection and they sorb well on active area. We considered the possibility to study enterosorption pectin capacity in relation to these pesticides by the example of citrus and apple pectins ("Medetopekt").

There 38 patients had been under observation with chronic pancreatitis with evident biological carrier status of organochlorine pesticides, 20 of them got citrus pectin as a monotherapy (according to the scheme), 18 patients had the same diet, but no pectin.

The testing results showed that the course citrus pectin therapy favored total excretion of organochlorine pesticides at $11.0 \%$ of the patients, at other patients pesticides concentration reduced up to minimal level of concentration determined by gas chromatographic method $\left(0.0001 \mathrm{mg} / \mathrm{dm}^{3}\right)$. There is a significant difference of values before and after pectin treatment. At the same time at patients who had not taken enterosorbent (compare group) the level of organochlorine pesticides after repeated tests stayed on the level close to the basic (Table 2).

In the case of an incomplete excretion of organochlorine pesticides the patients had been recommended retreatment of pectin course in 10-20 days.

There also had been examined 44 patients with duodenal ulcer and with evident carrier status of residual quantity of organochlorine pesticides. Concentration of organochlorine pesticides in blood in this category of patients was from 0.0008 to 
$0.0730 \mathrm{mg} / \mathrm{dm}^{3}$ of biosubstrate, 22 of the patients got "Medetopekt", 22 patients were in the compare group. The testing of detoxification activity of the enterosorbent had been organized under control of the $\alpha-, \beta-, \gamma$-hexachlorocyclohexane $(\mathrm{HCH})$ in whole blood by the method of gas-liquid chromatography.

The results of the study showed that after the course of "Medetopekt" at $\mathbf{2 8 . 6 \%}$ of the patients there had not been revealed any definable pesticides in blood. At other patients its concentration reduced up to $78.2 \%$. There are the results in Table 3 .

At the repeated test of $\mathrm{HCH}$ isomers in blood of the patients who had not been taken enterosorbent (group of compare), the concentration of these substances had been stayed on the level close to the basic $(p<0,05)$.

While studying the citrus pectin characteristics there had been estimated a surface hydration processes. To determine the position of citrus pectin among foreign and domestic equivalents of enterosorbents, there had been compared their electrochemical properties. Table 4 presents the following characteristics of sorbents water solutions: ORP - oxidation-reduction potential, $\mathrm{mV}$; $\mathrm{EC}$ - electrical conductivity, $\mathrm{mS} / \mathrm{cm}$; $\mathrm{pH}$ - relative units.

The indices were measured according to: current time of occurrence (10 $\mathrm{min})$, state equilibrium (saturation of solution) in condition of the experiment and for infiltration.

\section{Discussion}

On the base of the research we can ascertain that citrus and apple pectin "Medetopekt" reduce resorbtion of heavy metals and organochlorine pesticides, accelerate eliminating of these substances from an organism. The main pectin component is polygalacturonic acid connected by 1,4-glycosidic linkage into a threadlike macromolecule - it contains as free as etherified carboxy groups. Etherified carboxy groups define sorption properties and ability to form unsolvable complexes with metals pectinates, they exteriorize out of an organism. Maximal effective degree of pectin etherification is $50-60 \%$. The presence of free active groups of polygalacturonic acid define the property to connect metal ion with pectinates, which are eliminated out of an organism by excretion organs.

Subsidiary links of natural pectin detoxification effect mechanism are ion exchange and oxidation-reduction processes on its surface. Activation of these processes causes noncompensated charges, they present in big (comparing with coal and carbon-mineral sorbents) values of oxidation-reduction (-348 $\mathrm{mV}$ ) and electrokinetic potential of s-potentials (1.6 relative units $\mathrm{pH})$. Peaks of infrared spectrums of absorbtion of citrus pectin in $1300-1700 \mathrm{~cm}^{-1}$ area show that there are many hydroxyl groups in its structure. In $1000-1100 \mathrm{~cm}^{-1}$ and $2800-3000 \mathrm{~cm}^{-1}$ intervals carboxy groups. This causes presentation of pectin complexing properties, which behave as a natural conjugating agents that bind toxins with hydrophilic compounds (which are easy to eliminate).

As from the Table 4, the most values of oxidation-reduction and electrical conductivity are in citrus pectin (comparing with other studied enterosorbents). This shows the enhanced capability of pectin surface to adsorb cation heavy metals. At the same time pectin solutions are acescent, $\mathrm{pH}$ is 5.4-5.7, which also causes binding of heavy metals by this enterosorbent. The most supportive environment for pectin complexing with heavy metals is intestine at $\mathrm{pH}$ 7.1-7.6. Gastric acid reduces the capability of high etherified pectin to bind heavy metals, so medicinally medium- and low-etherified pectin is rather than high etherified pectin.

The mechanism of eliminating of organochlorine pesticides with the help of pectin is presented to us different and depends chiefly on physicochemical pectin properties, which represents hydrophilic colloid with a high sorption capacity. It is well known that organochlorine pesticides are eliminated from an organism with bilis, and pectins bind bile acids in intestine, and by that cause eliminating of pesticides. Insoluble compounds in natural enterosorbents improve intestinal function. Moreover, at acute chronic pancreatitis pectins reduce hyperenzymemia $[10,11]$.

\section{Conclusion}

Pectins are derivation of natural products, safe for an organism and have no precautions. After a course of these enterosorbents there is effective reduce of levels of toxic heavy metals (lead, cadmium) and organochlorine pesticides in biomedia of patients with digestive organs pathology, complicated by toxic influence of low intensity. Subsidiary positive effect of pectin treatment is the fact that they reduce cholesterin level in blood, have selective bind properties in relation to low-density lipoproteins. Break of resorption prevents fast postprandial sugar fasting blood level increased, which is important in diabetes.

\section{Conflict of interest: none declared.}

\section{Reference}

1. Avtsyn AP, Zhavoronkov AA, Rish MA. Human microelementosis. Medicine Publ., Moscow, Russia, 1991. [Text in Russian]

2. Alimonti A, Bocca B, Mattei D, Pino A. Biomonitoring of the Italian population to metals: reference values 1990-2009. Rapporti ISTISAN 10/22, 2010

3. Gnidoi IM. Dietary fibers in children hepatobiliary system treatment Pediatriya (Moscow) 2000; (5): 97-101. [Article in Russian]

4. Shashel VA, Nefedova LV, Tarasova LV, Nefedov PV, Perov UM, Nastenko VP. Medico-ecological atlas of Krasnodar region. Kuban State Medical Academy, Krasnodar, Russia, 2002. [Text in Russian]

5. Wildlife Monitoring and Krasnodar Region Environmental Control Report in 2005-2006. Peresvet Publ., Krasnodar, Russia, 2006. [Text in Russian]

6. Collection of methods of chemical connections defining in biological medias. Moscow, Russia, 1999. [Text in Russian]

7. Foydorov V.I. Analysis of serum inorganic elements: State-of-the-art. Klin Lab Diagn 2006; (4): 8-14. [Article in Russian]

8. Klisenko MA. Methods of pesticides trace amount defining. Kolos Publ., Moscow, Russia, 1997. [Text in Russian]

9. Sofina LI, Tekutskaya EE, Zarya NU, Gusaruk LR. Method of probe preparing for gas chromatographic determining of organochlorine pesticides in blood. Patent [Rus] №2414711, 26 Dec 2008.

10. Kagan US. Influence of pesticides on some pathological processes developing. Hygiene of the use, pesticides toxicology. Naukova Dumka Publ., Kiev, Ukraine, 1985. [Text in Russian]

11. Minushkin OM. Chronic pancreatitis: some aspects of pathology, diagnostics and treatment. Consicilium Medicum 2002; (1): 23-25. [Article in Russian]

\section{Authors:}

Elena E. Tekutskaya - PhD, Assistant Professor, Department of Radio Physics and Nanotechnologies, Kuban State University, Krasnodar, Russia. 